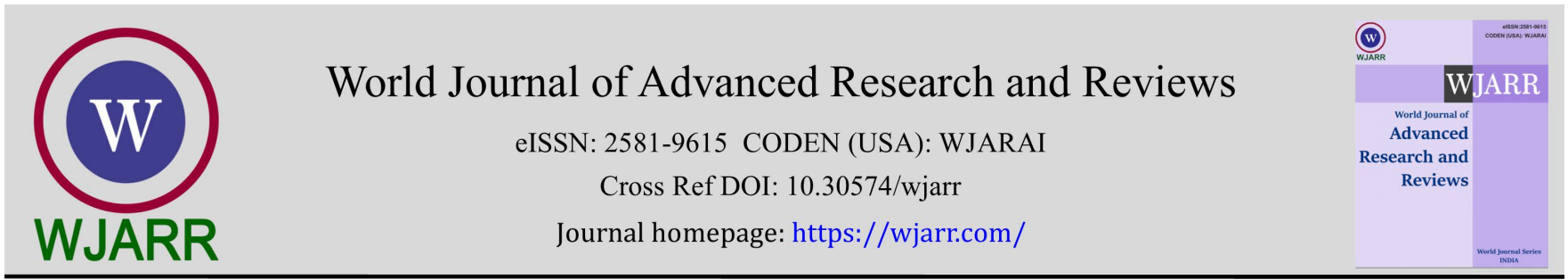

(RESEARCh ARTICLE)

\title{
Raising awareness and knowledge regarding gadget addiction during COVID-19 pandemic through webinar
}

\author{
Salsabila Firdausi Rafidah 1, Khansa Talitha Rafif 1, Sarah Nia Amru ${ }^{1}$ and Widati Fatmaningrum 2,* \\ ${ }^{1}$ Medical Program, Faculty of Medicine, Universitas Airlangga, Surabaya, Indonesia. \\ 2 Department of Public Health, Faculty of Medicine, Universitas Airlangga, Surabaya, Indonesia.
}

World Journal of Advanced Research and Reviews, 2022, 13(01), 332-337

Publication history: Received on 04 December 2021; revised on 09 January 2022; accepted on 11 January 2022

Article DOI: https://doi.org/10.30574/wjarr.2022.13.1.0008

\begin{abstract}
The COVID-19 pandemic challenged the public health sector and has impacted various sectors such as politics, education, economy, and socio-culture. As of 24 July 2021, there have been 3,127,826 confirmed cases of COVID-19 in Indonesia. Large-scale social restrictions, stay at home, online learning, and work from home have led people to change their ways of life. These may increase the duration and the need to use the gadget and may lead to addiction. We conduct a webinar to increase public knowledge and awareness regarding gadget addiction during the COVID-19 pandemic as a means to maintain general well-being. This study examines webinar participants' knowledge before and after the webinar. The participants were asked to fill a pre-test and a post-test. Thus the results were statistically examined to determine the knowledge difference before and after the webinar. The demographic data shows the webinar participants were dominated by female participants, people aged 17-25 years old, and high school graduates. The participants that are included in this study are 265 . There is an increase and significant difference $(p<0.05)$ between pre and post-test scores evaluated by Wilcoxon signed-rank test. The number of participants with low-level knowledge is reduced from 52 to 42 after the webinar. In conclusion, there is an increase in knowledge about gadget addiction in the era of the COVID-19 pandemic after the webinar based on the pre-test and post-test data. Thus, education through a webinar can be applied to increase the knowledge regarding gadget addiction during the COVID-19 pandemic.
\end{abstract}

Keywords: COVID-19; Gadget Addiction; Webinar; Knowledge

\section{Introduction}

COVID-19, the disease caused by a novel coronavirus named SARS-CoV-2, was first reported in Wuhan City, China, in December 2019 [1]. This disease has caused a global pandemic and spread worldwide, including in Indonesia. The two first cases of COVID-19 in Indonesia were discovered on 2 March 2020 [2]. According to Satgas COVID-19 [3], as of 24 July 2021, there have been 3,127,826 confirmed cases of COVID-19, including 574,135 active cases 2,471,678 cured cases, and 82,013 death cases. The COVID-19 pandemic challenged the public health sector and has impacted various public sectors such as politics, education, economy, and socio-culture [4]. The Indonesian government has implemented large-scale social restrictions in response to this global pandemic. Its purpose is to inhibit the spread of COVID-19 in Indonesia. Most individuals have spent more time at home, which may reduce or lose daily routine and structure. Moreover, being at home alone (or with family members), combined with uncertainty regarding the future and financial insecurity, may also contribute to heightened stress, anxiety, depression and a general decrease in psychological wellbeing [5].

The development of information and communications technology (ICT) makes it possible to communicate with others even during the pandemic. In the education sector, the application of online learning made it possible for students to

\footnotetext{
${ }^{*}$ Corresponding author: Widati Fatmaningrum

Department of Public Health, Faculty of Medicine, Universitas Airlangga, Surabaya, Indonesia.

Copyright (@ 2022 Author(s) retain the copyright of this article. This article is published under the terms of the Creative Commons Attribution Liscense 4.0.
} 
learn even when the traditional learning method characterized by face-to-face learning activities are temporarily stopped $[4,6]$. In the economic sector, both the government and the private sectors have implemented work from home (WFH) utilizing advanced ICT [7]. Not only for education and working but these technologies also can be used for digital entertainment. According to Lin [8], this pandemic has heightened digital entertainment using a gadget. The term "gadget" refers to the portable electronic devices that belong to either one or more of the following categories: mobile phones, MP3 players and gaming consoles or any other wireless-enabled devices [9].

However, the increased use of gadgets during the COVID-19 pandemic has been found to multiply the probability of addiction being a risk factor by two or more times $[5,10]$. The longer duration spent in front of a gadget may escalate to the level of gadget addiction [6]. Gadget addiction is characterized by an inability to control behaviour, inability to control the desire to play gadgets, problems with interpersonal relationships and emotional responses [11]. Gadget addicts may show other characteristics such as daily life disturbances, positive anticipation, withdrawal from social interactions, cyber-oriented relationships, excessive use of gadgets, and anti-tolerant [12]. Gadget addiction also disturbs the quality of sleep, which results in sleep deprivation [13,14]. Consistently, a study in India showed that university students who frequently use gadgets experience problems related to vision, hearing problems, difficulty in day to day work performance, disturbed sleep, concentrating problems, and reduced physical activity [11]. Frequent use of gadgets is also associated with symptoms of depression in young adults [15]. Another impact caused by excessive gadget use is cervical muscle tension, especially in the gamer community [16].

Based on the data shown above, we decided to hold a community service in a webinar to educate the public regarding gadget addiction during the pandemic. Webinar is a 'web-based seminar, in which students and teachers are connected live across distant geographical locations using shared virtual platforms and interact synchronously in real time via voice over IP and web camera equipment'. A webinar serves the educational function of learning and teaching [17]. We chose to hold a webinar as it is difficult to provide offline education with the risk of COVID-19. This webinar aims to increase public knowledge and awareness regarding gadget addiction during the COVID-19 pandemic. This study will examine the effect of webinar on participants' knowledge about gadget addiction during the pandemic.

\section{Material and methods}

The webinar was held on Saturday, 10 July 2021, through ZOOM meeting. The educational presentation was conducted for 1 hour, followed by 30 minutes question and answer session. The education session was presented by the resource person, dr. Brihastami Sawitri, Sp. KJ, through powerpoint slides. The education contents are: 1) Definition and epidemiology of gadget addiction, 2) Mechanism of gadget addiction, 3) Signs and symptoms of gadget addiction, 4) The impact of gadget addiction, 5) Prevention of gadget addiction during COVID-19 pandemic, 6) Management and how to reduce gadget addiction during COVID-19 pandemic. After that, the education session was followed by the question and answer session that was led by the moderator. In this session, the participants can ask questions to the resource person regarding gadget addiction during the pandemic.

We promote this webinar through social media for five days. We targeted the public, especially those who use social media. The webinar was attended by 571 participants. We evaluated the level of knowledge with PrePost analysis. Therefore, the participants were asked to fill the pre-test before the education session and the post-test after the question and answer session. There are fill in the blank questions for demographic data and 10 identical multiple-choice questions for pre-test and post-test. Both are conducted through Google form platform. Then, the results were statistically examined to determine the difference between pre-test and post-test score. We motivated the participants with e-certificate for those who attended the webinar, filled the pre-test and post-test, and e-money for the best posttest result.

We examined the respondents' characteristics by analyzing age, gender, and educational background. We classified the participants' pre-test and post-test scores into low $(<70)$, moderate (70-80), and high (90-100). The differences between pre-test and post-test scores were statistically examined by Wilcoxon signed-rank test if the distribution is not normal and Paired T-Test if the distribution is normal. We excluded the incomplete data and incomplete answers from our statistic examination. 


\section{Results}

\subsection{Demographic Characteristics}

The demographic characteristics of webinar participants are summarized in table 1 . The number of respondents that are met the inclusion criteria is 265. Most of the participants were aged 17-25 years old (54,15\%) and graduated from senior high school $(69,81 \%)$. The respondents who participated in this study were mostly female $(85,04 \%)$ compared to males $(13,96 \%)$. Most of them work as students $(95,60 \%)$.

Table 1 Demographic Characteristics of Webinar Participants ( $n=265)$

\begin{tabular}{|l|c|c|}
\hline \multirow{2}{*}{ Respondent Characteristics } & \multicolumn{2}{|c|}{ Respondent } \\
\cline { 2 - 3 } & $\mathbf{f}(\mathbf{2 6 5 )}$ & $\mathbf{\%}$ \\
\hline Age & 90 & 33.96 \\
\hline$<17$ years old & 170 & 64.15 \\
\hline 17-25 years old & 3 & 1.13 \\
\hline 26-35 years old & 2 & 0.75 \\
\hline 36-45 years old & 37 & 13.96 \\
\hline Gender & 228 & 85.04 \\
\hline Male & 3 & 1.13 \\
\hline Female & 60 & 22.64 \\
\hline Educational background & 185 & 69.81 \\
\hline Elementary School & 14 & 5.29 \\
\hline Middle School & 3 & 1.13 \\
\hline High School
\end{tabular}

\subsection{Gadget Addiction Knowledge}

Table 2 Descriptive Statistic of Pre-Test and Post-Test Score

\begin{tabular}{|c|c|c|c|c|c|c|c|c|}
\hline \multirow[t]{2}{*}{ Population } & \multicolumn{4}{|c|}{ Pre-Test } & \multicolumn{4}{|c|}{ Post-Test } \\
\hline & Min & Max & Mean & SD & Min & Max & Mean & SD \\
\hline \multicolumn{9}{|l|}{ Gender } \\
\hline Male & 20 & 90 & 45.41 & 16.43 & 10 & 80 & 48.11 & 15.95 \\
\hline Female & 10 & 90 & 49.56 & 16.33 & 10 & 90 & 52.94 & 16.49 \\
\hline \multicolumn{9}{|l|}{ Age } \\
\hline$<17$ years old & 10 & 90 & 49.77 & 16.53 & 10 & 90 & 52.50 & 16.70 \\
\hline 17-25 years old & 10 & 90 & 48.76 & 16.05 & 10 & 90 & 52.28 & 16.26 \\
\hline 26-35 years old & 20 & 80 & 48.00 & 24.94 & 30 & 80 & 56.00 & 20.54 \\
\hline $35-45$ years old & 30 & 40 & 35.00 & 5.00 & 40 & 60 & 50.00 & 10.00 \\
\hline \multicolumn{9}{|c|}{ Educational background } \\
\hline Elementary school & 30 & 80 & 33.33 & 11.57 & 40 & 80 & 56.67 & 30.55 \\
\hline Middle school & 10 & 90 & 48.36 & 17.82 & 10 & 90 & 49.18 & 17.65 \\
\hline High School & 10 & 90 & 50.05 & 15.52 & 10 & 90 & 53.48 & 15.71 \\
\hline Associate degree & 60 & 60 & 60.00 & - & 60 & 60 & 60.00 & - \\
\hline Bachelor degree & 20 & 80 & 42.31 & 20.87 & 30 & 80 & 46.92 & 17.97 \\
\hline Master's degree & 30 & 40 & 36.67 & 5.77 & 40 & 60 & 53.33 & 11.54 \\
\hline Total & 10 & 90 & 48.98 & 16.34 & 10 & 90 & 52.26 & 16.44 \\
\hline
\end{tabular}


In the results section below, namely table 2, there are minimum and maximum pre-test and post-test scores in our webinar, which indicate the minimum and maximum scores from the Gender, Age, and Education aspects. The elaboration of several aspects in the pre-test table, the minimum value is 10 , and the maximum is 90 . At the same time, the post-test section is also the same, namely a minimum of 10 and a maximum of 90 .

Then in table 3, which is the Wilcoxon Signed Rank Test Result table, the average value (mean) of the participants in the webinar that we conduct is $48.98 \pm 16.34$ for the pre-test and $52.26 \pm 16.44$ for the post-test. Based on the results of the tests carried out, the results of the Wilcoxon statistical test were obtained: a significance value of 0.001 , which is less than 0.005 , which means that there is an influence from the webinar held regarding the level of public knowledge about gadget addiction in the current Covid-19 pandemic era.

Table 3 Result of Wilcoxon Signed Rank Test

\begin{tabular}{|l|c|c|c|c|c|c|}
\hline \multirow{2}{*}{ Level of knowledge } & \multirow{2}{*}{ Pre-test } & \multirow{2}{*}{ Post-test } & \multicolumn{3}{|c|}{ Rank } & \multirow{2}{*}{ P } \\
\cline { 4 - 6 } & & & Negative & Positive & Ties & \\
\hline Low & 52 & 42 & 65 & 121 & 79 & 0.001 \\
\hline Moderate & 170 & 169 & & & & \\
\hline High & 43 & 54 & & & & \\
\hline Mean & 48.98 & 52.26 & & & & \\
\hline
\end{tabular}

\section{Discussion}

The COVID-19 pandemic has challenged the public health sector and has impacted various sectors such as politics, education, economy, and socio-culture. The increased time at home during the pandemic imposed the risk of gadget addiction. According to Király et al. [5] and Winther and Byrne [10], the increased use of gadgets during the COVID-19 pandemic has been found to multiply the probability of it being a risk factor for addiction by two or more times. Therefore, the public's knowledge and awareness play a vital role to prevent gadget addiction during the pandemic.

The participants of this webinar are dominated by people aged 17-25 years old (64.15\%) and females (85.04\%). According to a study by Smith and Anderson [18], people aged 18-24 years old in USA are the major users of social media platforms. This result is similar to a study by Nurhayati-Wolff [19] that shows that people aged 18-24 years old are the second-highest social media users in Indonesia. This correlates with the promotion of this webinar, as we have done it through social media [19]. Therefore, the accessibility and the probability of people knowing about this webinar is higher for people in those age groups. The higher participation rate of females in webinars than that of males is supported by a survey that discusses the reality of webinar activities during a pandemic. It shows that the number of webinar participants is dominated by women (67\%), whose population comes from academics, students, and education staff [20]. Moreover, women were significantly more interested in health-related information, much more active in seeking health-related information, and paid more attention to potential worldwide pandemics than males [21].

Based on the Wilcoxon signed-rank test, there is an increase between pre-test and post-test scores. The pre-test mean score is $48.98 \pm 16.34$, which falls into the low-level knowledge category, and the post-test mean score is $52.26 \pm 16.44$, which also falls into the low-level knowledge category. However, although both pre-test and post-test scores still fall into the low-level knowledge category, our study shows a significant difference $(\mathrm{p}<0.05)$ between the scores. A similar study by Sebayang et al. [22] shows an increase in knowledge about gadgets and smartphone addiction after online socialization.

The result of post-test correlates with webinar effectiveness that is affected by many boundary conditions. The frequency, duration, and length of webinars can moderate the webinar effectiveness [17]. A survey by LLDIKTI V [20] shows $85,3 \%$ of people can focus during webinar for 1-2 hours. If the duration is longer than 90 minutes, it is feared that participants, especially the general public, cannot concentrate during the webinar [23]. The education session in this webinar was 1 hour long followed by 30 minutes answer and question session. The duration of this webinar can be the factor of an increase in post-test scores.

In addition, participants' characteristics such as gender and age can affect webinar effectiveness [17]. The level of knowledge for women based on the average score of the pre-test score was $49.56 \pm 16.33$ and for the post-test was 
52.94 \pm 16.49 . Meanwhile, for men, the average score of pre-test and post-test were $45.41 \pm 16.43$ and $48.11 \pm 15.95$. Therefore, it shows that female participants have a higher level of knowledge regarding gadget addiction during the pandemic than male participants. It correlates with previous studies that show female is more active in seeking healthrelated information [21, 24]. This behaviour can be the factor as to why female participants have more knowledge regarding gadget addiction than male participants. Participants aged 26-35 years old have the highest post-test mean scores with $56.00 \pm 20.54$. This shows that age affects the level of knowledge [25].

We are aware that further education and health promotion to raise the knowledge about gadget addiction during the pandemic is needed. Especially during the COVID-19 pandemic, there is interaction limitation and a higher risk of gadget addiction. First, to increase the webinar effectiveness for education, the interaction between the resource person and the participants must be increased. The increased interaction contributes to higher learning, transfer, and understanding. Increased interaction can be done through discussion after or during the webinar; the participants are divided into small groups [23]. Health promotion containing knowledge about gadget addiction can be delivered through print media such as booklets, leaflets, rubik's and posters; electronic media such as video; and outdoor media such as billboards and banners [26]. Social media can be used as a platform for health promotion, especially as a platform to spread knowledge and information regarding gadget addiction during pandemics [27].

\section{Conclusion}

There is an increase in knowledge after the webinar based on the statistical examination of pre-test and post-test data. Thus, education through webinars can be applied to increase the knowledge regarding gadget addiction during the COVID-19 pandemic.

\section{Compliance with ethical standards}

\section{Acknowledgments}

The authors would like to thank all those who have helped in writing this article.

\section{Disclosure of conflict of interest}

The authors declare that there is no conflict of interest.

\section{Statement of informed consent}

Informed consent has been obtained from each respondent when filling out the pre-test and post test.

\section{References}

[1] WHO. Coronavirus disease 2019 (COVID-19) Situation Report - 94. [Internet]. (C) 2020.

[2] Nugraha B, Wahyuni L, Laswati H, Kusumastuti P, Tulaar A, Gutenbrunner C. COVID-19 pandemic in Indonesia: Situation and challenges of rehabilitation medicine in Indonesia. Acta Medica Indonesiana. 2020; 52(3): $299-305$.

[3] Satgas COVID-19. Peta Sebaran. [Internet]. Satuan Tugas Penanganan COVID-19; (C) 2021.

[4] Abidah A, Hidayatullaah H, Simamora R, Fehabutar D, Mutakinati L. The Impact of Covid-19 to Indonesian Education and Its Relation to the Philosophy of "Merdeka Belajar". Studies in Philosophy of Science and Education. 2020; 1(1): 38-49.

[5] Király O, Potenza MN, Stein DJ, King DL, Hodgins DC, Saunders JB, Griffiths MD, Gjoneska B, Billieux J, Brand M, Abbott MW, Chamberlain SR, Corazza O, Burkauskas J, Sales CMD, Montag C, Lochner C, Grünblatt E, Wegmann E, Martinotti G, Lee HK, Rumpf HJ, Castro-Calvo J, Rahimi-Movaghar A, Higuchi S, Menchon JM, Zohar J, Pellegrini L, Walitza S, Fineberg NA, Demetrovics Z. Preventing problematic internet use during the COVID- 19 pandemic: Consensus guidance. Comprehensive Psychiatry. 2020; 100: 152180.

[6] Widodo A, Wartoyo FX. Lockdown and Gadget Addicted Phenomenon, in The 4th ICLIQE. 2020.

[7] Mungkasa O. Bekerja dari Rumah (Working From Home/WFH): Menuju Tatanan Baru Era Pandemi COVID 19. Jurnal Perencanaan Pembangunan: The Indonesian Journal of Development Planning. 2020; 4(2): $126-150$. 
[8] Lin MP. Prevalence of Internet Addiction during the COVID-19 Outbreak and Its Risk Factors among Junior High School Students in Taiwan. Int. J. Environ. Res. Public Health. 2020; 17: 8547.

[9] Gupta N, Krishnamurthy V, Majhi J, Gupta S. Gadget Dependency among Medical College Students in Delhi. Ind J Comm Health. 2013; 25(4): $362-366$.

[10] Winther DK, Byrne J. Rethinking screen-time in the time of COVID-19. [Internet]. UNICEF; (C) 2020.

[11] Kumar K, Sherkhane MS. Assessment of gadgets addiction and its impact on health among undergraduates. Int. J. Community Med. Public Heal. 2018; 5(8): 3624.

[12] Hijrianti UR, Amalia S. Development of Measurement Tool of Smartphone-Addicted Indication for Middle-Aged Children, in Proceedings of the 4th ASEAN Conference on Psychology, Counselling, and Humanities (ACPCH 2018). 2019; 322-325.

[13] Xanidis N, Brignell CM. The association between the use of social network sites, sleep quality and cognitive function during the day. Computers in Human Behavior. 2016; 55: 121-126.

[14] Alimoradi Z, Lin CY, Broström A, Bülow PH, Bajalan Z, Griffiths MD, Ohayon MM, Pakpour AH. Internet addiction and sleep problems: A systematic review and meta-analysis. Sleep Medicine Reviews. W. B. Saunders Ltd. 2019.

[15] Thomée S, Härenstam A, Hagberg M. Mobile phone use and stress, sleep disturbances, and symptoms of depression among young adults--a prospective cohort study. BMC Public Health. 2011; 11: 66.

[16] Rijal Rini I, Rabia, Lestari NT. The correlation between gadget usageand cervical muscle tension among the community of gamers. Enfermería Clínica. 2020; 30: 149-153.

[17] Gegenfurtner A, Ebner C. Webinars in higher education and professional training: A meta-analysis and systematic review of randomized controlled trials. Educational Research Review. 2019; 28: 100293.

[18] Smith A, Anderson M., Social Media Use in 2018. [Internet]. Pew Research Center; (c) 2018.

[19] Nurhayati-Wolff, H. Breakdown of social media users by age and gender in Indonesia as of January 2021. [Internet]. Statista C. 2021.

[20] Lldikti V. Realitas Webinar di Masa Pandemi - Website LLDIKTI Wilayah V. [Internet]. Kemdikbud (C. 2020.

[21] Ek S. Gender differences in health information behaviour: a Finnish population-based survey, Health Promotion International. 2015; 30(3): 736-745.

[22] Sebayang SK, Dewi DMSK, Puspikawati SI, Astutik E, Lailiyah S, Aini EQ, Hariyani RP. Pengembangan Kesadaran Tentang Kecanduan Gawai Dan Telepon Pintar Pada Remaja Di Kabupaten Banyuwangi, Indonesia. Journal of Community Mental Health and Public Policy. 2021; 3(1): 41-47.

[23] Gegenfurtner A, Zitt A, Ebner C. Evaluating webinar-based training: a mixed methods study of trainee reactions toward digital web conferencing. International Journal of Training and Development. 2020; 24(1): 5-21.

[24] Renahy E, Parizot I, Chauvin P. Determinants of the frequency of online health information seeking: results of a web-based survey conducted in France in 2007. Informatics for health \& social care. 2010; 35(1): 25-39.

[25] Diyanah KC, Damayanti R. Knowledge Enhancement About Covid-19 Prevention On Community With Webinar Program. Journal of Public Service. 2021; 5(1): 103-110.

[26] Jatmika SED, Maulana M, Kuntoro Martini S. BUKU AJAR PENGEMBANGAN MEDIA PROMOSI KESEHATAN. Yogyakarta: Penerbit K-Media. 2019.

[27] Welch V, Petkovic J, Pardo Pardo J, Rader T, Tugwell P. Interactive social media interventions to promote health equity: an overview of reviews. Health promotion and chronic disease prevention in Canada : research, policy and practice. $2016 ; 36(4)$ : 63-75. 